\title{
Anions effect on the low temperature growth of $\mathrm{ZnO}$ nanostructures
}

Mazhar Ali Abbasi, Yaqoob Khan, Sajjad Hussain, Omer Nur and Magnus Willander

\section{Linköping University Post Print}

N.B.: When citing this work, cite the original article.

Original Publication:

Mazhar Ali Abbasi, Yaqoob Khan, Sajjad Hussain, Omer Nur and Magnus Willander, Anions effect on the low temperature growth of $\mathrm{ZnO}$ nanostructures, 2012, Vacuum, (86), 12, 19982001.

http://dx.doi.org/10.1016/j.vacuum.2012.05.020

Copyright: Elsevier

http://www.elsevier.com/

Postprint available at: Linköping University Electronic Press

http://urn.kb.se/resolve?urn=urn:nbn:se:liu:diva-84909 


\title{
Anions effect on the low temperature growth of $\mathrm{ZnO}$ nanostructures
}

\author{
Mazhar Ali Abbasi $^{1 *}$, Yaqoob Khan ${ }^{2}$, Sajjad Hussain ${ }^{1}$, Omer Nur $^{1}$, Magnus Willander ${ }^{1}$ \\ 1. Department of Science and Technology, Linköping University, Campus Norrköping, SE-60174 \\ Norrköping, Sweden. \\ 2. Department of Physics, Chemistry and Biology (IFM) Linköping University, Linköping SE-58183, \\ Sweden.
}

\begin{abstract}
:
Seed mediated aqueous chemical growth (ACG) route was used for the growth of $\mathrm{ZnO}$ nanostructures on Si substrate in four different growth mediums. The growth medium has shown to affect the morphology and the size of the different nanostructures. We observed that the medium containing zinc nitrate anions yields the nanorods, in a medium containing zinc acetate anions nano-candles are obtained. While in a medium containing zinc chloride anions $\mathrm{ZnO}$ nano-discs were obtained and in a medium containing zinc sulfate anions nano-flakes are achieved. Growth in these different mediums has also shown effect on the optical emission characteristics of the different $\mathrm{ZnO}$ nanostructures.
\end{abstract}

Key words: $\mathrm{ZnO}$, chemical growth, nanostructures, optical properties

\section{Corresponding author:}

*Mazhar Ali Abbasi, (mazhar.ali.abbasi@liu.se) 
$\mathrm{ZnO}$ is an unintentionally doped n-type semiconductor material with a relatively large exciton binding energy of $60 \mathrm{meV}$ and large band gap energy of $3.37 \mathrm{eV}$ at room temperature [1]. During the last two decades, $\mathrm{ZnO}$ has attracted the interest of researchers due to its potential applications in dye-sensitized solar cells [2], sensors [3], nano lasers [4], field effect transistors [5], light emitting diodes [6], and other applications [7].

Nowadays there are many techniques used for the growth of $\mathrm{ZnO}$ nanostructures such as chemical vapor deposition (CVD) [8], plasma enhanced chemical vapor deposition (PECVD) [9], pulsed laser deposition (PLD) [10], molecular beam epitaxy (MBE) [11], low temperature solution routes [12] and electrodeposition [13]. All these methods produce high quality single crystal $\mathrm{ZnO}$ nanostructure, but the requirement of high temperature limits the compatibility of growth e.g. on organic substrates for applications in the field of flexible electronics [14]. The low temperature hydrothermal synthesis has been widely used for the growth of $\mathrm{ZnO}$ nanostructures on different substrates, mainly because of its simplicity, cost effectiveness and the ability to produce various nanostructures on large scale [15]. Well oriented and good quality of $\mathrm{ZnO}$ nanostructures grown at low temperatures are comparable to other methods $[1,1415]$.

In the hydrothermal synthesis, different parameters such as the type of the precursor used, the additives, the solvents, and the $\mathrm{pH}$ of the growth medium all play an important role in the growth of $\mathrm{ZnO}$ nanostructures. The diversity of the well-defined morphology of $\mathrm{ZnO}$ by decomposing $\mathrm{Zn}(\mathrm{OH})_{4}^{2-}$ or $\mathrm{Zn}\left(\mathrm{NH}_{4}\right)_{2}^{+}$precursors in different solvents at suitable reaction conditions was reported by Yan et al. [16]. Que D.L. et al. 
and $\mathrm{Yan}$ et al. reported that in the synthesis of $\mathrm{ZnO}$ nano-flowers the $\mathrm{pH}$ value is a key factor $[16,17]$.

Changing the $\mathrm{Zn}$ precursor might be an efficient way to introduce different anions into the growth medium and opens up new possibilities to engineer the type and dimensions of $\mathrm{ZnO}$ nanostructures grown under the same conditions [18]. In 2008, Levy-Clement.C. et al. reported that significant variations in the diameter and lengths of nanowires can be obtained by only changing the nature of the anions in the growth solution [18]. In 2011, effect of anions of zinc salts on the formation of $\mathrm{ZnO}$ nanostructures in a closed cylindrical Teflon-linded stainless steel by the hydrothermal process was reported by Jaing. Q. et al. [19].

To the best of our knowledge there is no single study which addresses the effect of anions on the morphology of $\mathrm{ZnO}$ nanostructures grown by the low temperature aqueous chemical growth (ACG) route. In this paper we report the effects of four different anions i.e. sulfate, nitrate, acetate and chloride on the growth of $\mathrm{ZnO}$ nanostructures at low temperature by the ACG. The presence of different anions in the growth mediums resulted in different morphologies of $\mathrm{ZnO}$ nanostructures such as nanorods, nano-candles, nano-disks, and nano-flakes. In addition to this, the optical property of the $\mathrm{ZnO}$ nanostructures has also been affected by the presence of different anions in growth mediums.

All chemicals were purchased from Sigma Aldrich, and used without any further purification. In this experiment we used zinc nitrate, zinc acetate, zinc chloride and zinc sulfate as anions for varying the growth mediums.

$\mathrm{ZnO}$ nanostructures were grown on p-type silicon substrates using the low temperature aqueous chemical growth route. The substrates were cleaned ultrasonically 
in acetone, ethanol and isopropyl alcohol (IPA) each for 15 minutes, and then they were rinsed thoroughly with de-ionized water. $\mathrm{ZnO}$ seed layer was deposited using a solution which contains zinc acetate and ethanol on each silicon wafer by spin coating at 3000r.p.m. This procedure was repeated three times and after that the substrates were annealed at $200^{\circ} \mathrm{C}$ for 30 minutes. The growth solutions for $\mathrm{ZnO}$ were prepared by equal molar ratio of 1:1 for all precursors. We prepared the first solution by $0.1 \mathrm{M}$ of zinc nitrate $+0.1 \mathrm{M}$ of Hexamethylenetetramine (HMT), the second solution was $0.1 \mathrm{M}$ of zinc acetate $+0.1 \mathrm{M}$ of HMT, the third solution $0.1 \mathrm{M}$ of zinc chloride $+0.1 \mathrm{M}$ of HMT and finally for the fourth solution we used $0.1 \mathrm{M}$ of zinc sulfate $+0.1 \mathrm{M}$ of HMT, in $150 \mathrm{ml}$ of deionized water and all solutions were left on stirring at $50^{\circ} \mathrm{C}$ for 30 minutes.

Finally we put the pre-coated substrates horizontally inside the beakers containing the precursor solutions and cover the beakers by aluminum foil, after that we placed all the beakers in a regular laboratory oven at $90^{\circ} \mathrm{C}$ for 6 hours. After the completion of growth time, the substrates were directly washed with deionized water and dried at room temperature.

The grown $\mathrm{ZnO}$ nanostructures were characterized by various techniques such as field emission scanning electron microscopy (FE-SEM) using a LEO 1550 Gemini microscope to investigate the morphology of the $\mathrm{ZnO}$ nanostructures. While the structures were analyzed using X-ray diffraction (XRD) by a Philips PW 1729 diffractomter utilizing $\mathrm{Cu}_{\mathrm{k} \alpha}$ and finally photoluminescence (PL) measurements were performed at room temperature using a coherent MBD266 laser. 
Figure 1(a-d) shows the SEM images of different $\mathrm{ZnO}$ nanostructures grown under the effect of different anions such as nitrates, acetates, chlorides and sulfates. Figure 1(a) shows $\mathrm{ZnO}$ nanorods with an average diameter of $150 \mathrm{~nm}$ and an average length of $4 \mu \mathrm{m}$ grown in a zinc nitrate solution, under the effect of nitrate which used as anion in the growth solution. Here we obtained a smooth, dense growth and almost all the nanorods were perpendicular to the surface of the substrate. Figure 1(b) shows a candle like nanostructures with an average diameter of $300 \mathrm{~nm}$ and a length of about $800 \mathrm{~nm}$ grown under the effect of acetate anions using a solution of zinc acetate. Figure 1(c) shows the behavior of chloride anions in the growth solution of zinc chloride during the growth of $\mathrm{ZnO}$ nanostructures. We obtained a disc like nanostructures with a diameter of $150-250 \mathrm{~nm}$ and a length of about $200-250 \mathrm{~nm}$. Finally figure $1(\mathrm{~d})$ shows flakes like $\mathrm{ZnO}$ nanostructure grown under the effect of sulfate anions in the growth solution. The average thickness of the flakes is about $50 \mathrm{~nm}$ and the width is about $10 \mu \mathrm{m}$.

Figure 2 shows XRD patterns of different $\mathrm{ZnO}$ nanostructures. Based on the peak positions, all the XRD patterns were indexed to hexagonal wurtzite phase of $\mathrm{ZnO}$ consistent with the JCPDS No. 36-1451 file. However, figure 2 (a-d) shows that the intensity of the 002 peaks is higher compared to the other peaks in the XRD pattern, which gives strong evidence about the preferential growth of $\mathrm{ZnO}$ nanostructures along the c-axis [20]. Also in figure 2(d) we observed that the XRD peaks were broader as compare to figures $2(\mathrm{a}-\mathrm{c})$. This is due to the effect of sulfate anions which suppressed the crystal size. By using the Bragg's law and the Scherer's formula, we calculated the lattice parameters, spacing and the size of the grown $\mathrm{ZnO}$ nanostructures with respect to (002) crystal plane as given in table1. 

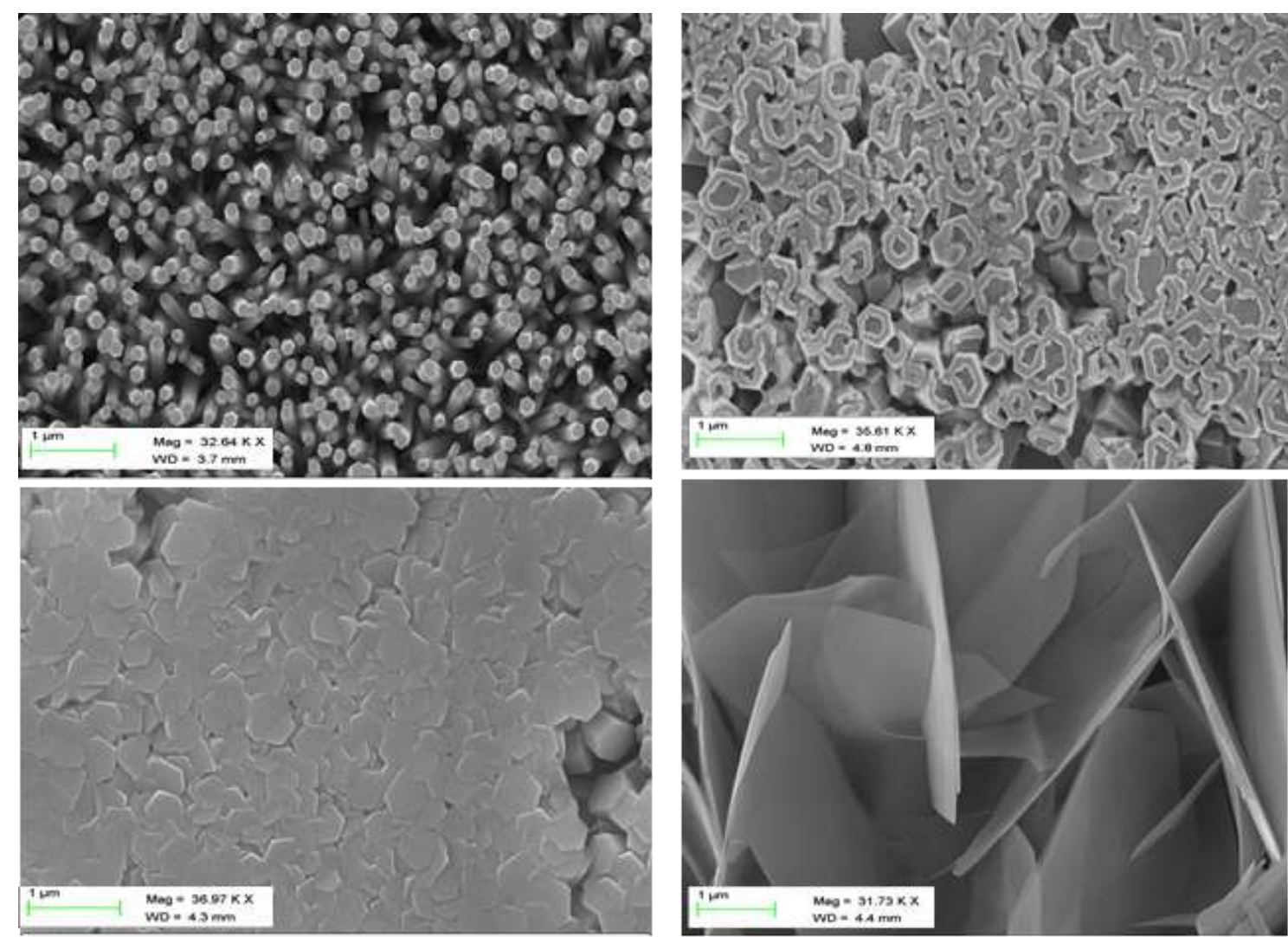

\section{Figure 1:}

The low and high magnification SEM images of different $\mathrm{ZnO}$ nanostructures grown in (a) zinc nitrate, (b) zinc acetate, (c) zinc chloride and (d) zinc sulfate 

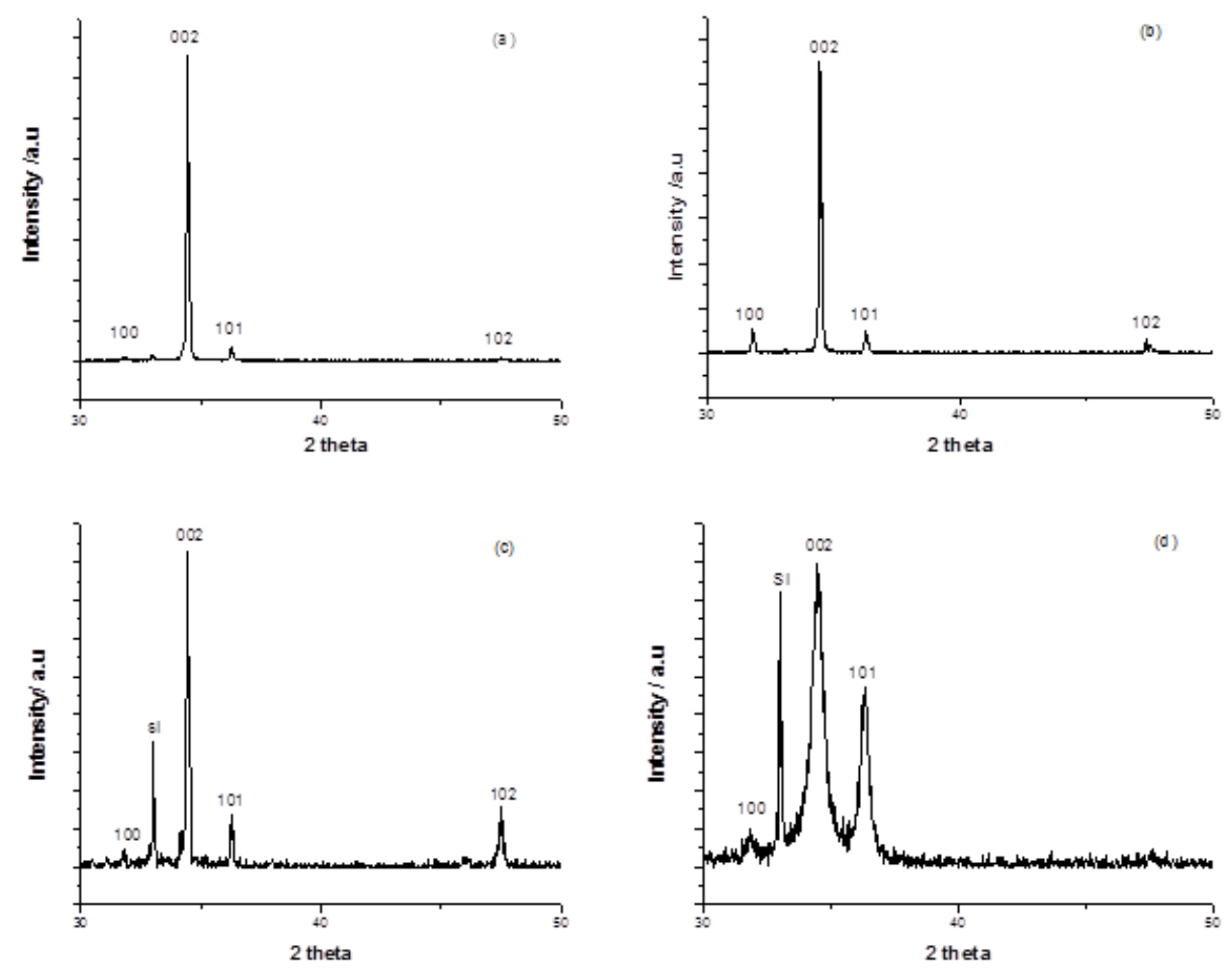

\section{Figure 3:}

PL spectra of different structures grown in different growth mediums (a) zinc nitrate, (b) zinc acetate, (c) zinc chloride and (d) zinc sulfate

As far as the growth of $\mathrm{ZnO}$ crystals is concerned, the crystals exhibited different growth behavior, which is depending on the relative growth rates of various crystal facets under hydrothermal conditions. The growth velocities of the $\mathrm{ZnO}$ crystal is different along the $[0001]>[01 \overline{1} \overline{1}]>[01 \overline{1} 0]>[01 \overline{1} 1]>[000 \overline{1}]$ directions [21]. A $\mathrm{ZnO}$ polar crystal has positively charged [0001]-Zn terminated and negatively charged $\mathrm{O}$ [0001] polar surfaces. It is reported that the $\mathrm{Zn}$ [0001] surface is chemically active for the growth of nanostructures while the $\mathrm{O}$ [0001] surface is inert [22]. 


\section{Table 1.}

Shows the lattice parameters, spacing and the dimensions calculated at (002) plane of $\mathrm{ZnO}$ nanostructure grown in the different mediums.

\begin{tabular}{|c|c|c|c|c|c|}
\hline Diffract gram & $\mathbf{a}(\stackrel{\AA}{\mathbf{A}})$ & $\mathbf{c}(\stackrel{\AA}{)})$ & $\mathbf{d}(\stackrel{\AA}{\mathbf{A}})$ & FWHM & thickness( $\mathbf{A})$ \\
\hline $\mathbf{a}$ & 1.2 & 5.2 & 2.6 & 0.10 & 818.4 \\
\hline $\mathbf{b}$ & 1.2 & 5.2 & 2.6 & 0.11 & 758.0 \\
\hline $\mathbf{c}$ & 1.2 & 5.2 & 2.6 & 0.16 & 521.3 \\
\hline $\mathbf{d}$ & 1.2 & 5.2 & 2.6 & 0.50 & 166.7 \\
\hline
\end{tabular}

It is suggested that the zinc nitrate is more favorable for the growth of $\mathrm{ZnO}$ nanostructures for the hydrothermal growth method due to the preferential growth of $\mathrm{ZnO}$ nanorods along the [0001] and also the fast growth rate along that direction is supported by the zinc nitrate in the growth solution [23]. For the formation of candles like structures, the growth process has two sequential steps with different conditions. It has been suggested that the polar planes having higher surface energies are less stable than the nonpolar planes with relatively lower surface energy. Due to this the non-polar planes are more stable than the polar planes [24]. Therefore the dissolution rate of the meta stable [0001] planes is faster than the other six symmetric non polar planes [25]. So we can say that in the case of the candles, acetate anions in the growth solution were adsorbed at the [0001] planes during the growth of the $\mathrm{ZnO}$ crystals and resulted in the shape of candles type nanostructures [25].

As far as the growth of the nano-discs is concerned, it has been observed that the nano-discs were formed due to the suppression of the growth along the [0001] direction 
under certain experimental conditions and the growth proceed along the six directions of the [0110] planes, which have the lowest surface energy. Keeping in mind that the continuous growth in the six [0110] directions leads to the formation of hexagonal nano-discs [26]. The basic process for the formation of the $\mathrm{ZnO}$ nano-flakes using zinc sulfate is almost identical to that of the $\mathrm{ZnO}$ nano-discs with the difference of the growth direction. Regarding the growth of the $\mathrm{ZnO}$ nano-flakes, the growth was observed to be along the c-axis orientation and equally along two more directions. It is due to the sulphate anions that may block some active sites of $\mathrm{ZnO}$ surface. Hence the growth proceeds in more than one direction and leads to the formation of nano-flakes structure [22]. This is confirmed when comparing the intensity of the [101] peak in figure $2 \mathrm{~d}$ with those where the sulfate anions were not used (figure $2 \mathrm{a}-\mathrm{c}$ ).

To study the influence of the different anions on the optical properties of the grown $\mathrm{ZnO}$ nanostructures, $\mathrm{PL}$ measurements were conducted at room temperature and the results are presented in figure 3. All the PL spectra show a dominant UV emission peak at around $380 \mathrm{~nm}$ resulted from the recombination of free excitons in the band gap. This indicates that the grown crystals of the different $\mathrm{ZnO}$ nanostructures are of good quality. While a broad green emission at $528 \mathrm{~nm}$ was observed due to the deep level defects in the $\mathrm{ZnO}$ crystals $[15,27,28]$. Based on our observation, we concluded that the intensities are different in the visible region of the PL spectra due to the possible effect of anions in the growth mediums. It is reported in the literature that more singly ionized vacancy defects will result in higher green PL intensities [15]. By comparing all these spectra, we concluded that the $\mathrm{ZnO}$ nanostructure grown in zinc nitrate medium has higher deep level defects as compared to others. While $\mathrm{ZnO}$ nanostructures grown in zinc chloride has the lowest deep level defects as compared to other samples. 
In conclusion we observed that in the growth of $\mathrm{ZnO}$ nanostructures, anions play a very important role to control the morphology and crystal quality. In our study it has been observed that probably we may control the growth rate of different planes of $\mathrm{ZnO}$ crystals and get different structures only by changing the anions in the growth solution. It was also observed that anions affect the intensity of the deep level emission. It is believed that further investigations in this regard will help to understand the growth mechanism and the different properties of $\mathrm{ZnO}$ crystals grown in different growth mediums.

\section{References:}

[1]. S.-F. Wang, T.-Y. Tseng, Y.-R. Wang, C.-Y. Wang, H.-C. Lu. Ceram. Int. 35 (2009) 1255-1260.

[2]. M. Law, L. E. Greene, J. C. Johnson, R. Saykally, P. Yang, Nat. Mater. 4 (2005) 455-459.

[3]. L. Chow, O. Lupan, G. Chai, Phys. Status Solidi B. 247 (2010) 1628-1632.

[4]. H. Zhou, M. Wissinger, J. Fallert, R. Hauschild, F. Stelzl, C. Klingshirn, H. Kalt, Appl. Phys. Lett. 91 (2007) 181112-181113.

[5]. S.-Y. Lee, A. Umar, D.-I. Suh, J.-E. Park, Y.-B. Hahn, J.-Y. Ahn, S.-K. Lee, Physica E. 40 (2008) 866-872.

[6]. N. H. Alvi, M. Willander, O. Nur, Superlattices and Microstruct. 47, (2010) 754761.

[7]. H. Wei, Y. Wu, N. Lun, C. Hu, Materials Science and Engineering: A. 393 (2005) 80-82.

[8]. J. J. Wu, S. C. Liu, Adv. Mater. 14 (2002) 215-218.

[9]. X. Liu, X. Wu, H. Cao, R.P.H. Chanh, J. Appl. Phys. 95 (2004) 3141-3147. 
[10]. J.-L. Zhao, X.-M. Li, J.-M. Bian, W.-D. Yu, X.-D. Gao, J. Cryst. Growth 276 (2005) 507-512.

[11]. D. C. Look, D. C. Reynolds, C. W. Litton, R. L. Jones, D. B. Eason, G. Cantwell, Appl. Phys. Lett. 81 (2002) 1830-1832.

[12]. Y. Khan, S. K. Durrani, M. Mehmood, J. Ahmad, M. R. Khan, S. Firdous, Appl. Surf. Sci. 257 (2010) 1756-1761.

[13]. J. Qiu, M. Guo, M. Zhang, X. Wang, J. Nanosci. Nanotechnol. 11 (2011) 49574967.

[14]. S. Zhang, Y. Shen, H. Fang, S. Xu, J. Song, Z. L. Wang, J. Mater. Chem. 20 (2010) 10606-10610.

[15]. M. Guo, P. Diao, S. Cai, J. Solid State Chem. 178 (2005) 1864-1873.

[16]. J. Zhang, L.D. Sun, J. L. Yin, H. L. Su, C. S. Liao, C. H. Yan, Chem. Mater. 14 (2002) 4172-4177.

[17]. H. Zhang, D. R. Yang, X. Y. Ma, Y. J. Ji, J. Xu, D. L. Que, Nanotechnology. 15 (2004) 622-626.

[18]. J. Elias, R. Tena-Zaera, C. Levy-Clement, J. Phys. Chem. C. 112 (2008) 57365741

[19]. Y. Lin, Q. Jiang, Applied Surface Science. 257 (2011) 8728-8731.

[20]. B. Yang, A. kumar, H. Zhang, P. Feng, R. S. Katiyar, Z. Wang, J. Phys. D: Appl. Phys. 42 (2009) 045415.

[21]. W.-J. Li, E.-W. Shi, W.-Z. Zhong, Z.-W. Yin, J. Cryst. Growth. 203 (1999) 186196.

[22]. P. X. Gao, Z. L. Wang, J. Phys. Chem. B. 108 (2004) 7534-7537.

[23]. L. Vayssieres, Advanced Materials. 15 (2003) 464-466. 
[24]. L. Vayssieres, K. Keis, A. Hagfeldt, S. E. Lindquist, Chem. Mater. 13 (2001) 4395-4398.

[25]. S. Cho, S.-H. Jung, K.-H. Lee, J.Phys. Chem. C. 112 (2008) 12769-12776.

[26]. U. Ahmad, Y.B. Hahn, Nanotechnology. 17 (2006) 2174-2180.

[27]. M.H. Huang, Y. Wu, H. Feick, N. Tran, E. Weber, P. yang, Adv. Mater. 13 (2001) 113-116.

[28]. K. Vanheusden, W. L. Warren, C. H. Seager, D. R. Tallant, J. A. Voigt, B. E. Gnade, J. Appl. Phys. 79 (1996) 7983-7990. 